07;09

\title{
Повышение эффективности интегрально-оптического сверхпроводящего датчика одиночных фотонов на подложке ниобата лития за счет дополнительного покровного слоя с высоким показателем преломления
}

\author{
(C) М.В. Парфенов ${ }^{1,2}$, А.В. Шамрай ${ }^{1}$ \\ ${ }^{1}$ Физико-технический институт им. А.Ф. Иофрфе РАН, Санкт-Петербург, Россия \\ ${ }^{2}$ Санкт-Петербургский политехнический университет Петра Великого, Санкт-Петербург, Россия \\ E-mail: mvparfenov@mail.ioffe.ru
}

Поступило в Редакцию 17 апреля 2020 г.

В окончательной редакции 17 апреля 2020г.

Принято к публикации 18 мая 2020г.

\begin{abstract}
Исследован механизм усиления взаимодействия оптического излучения со сверхпроводящей пленкой нитрида ниобия на поверхности оптических волноводов на подложке ниобата лития при использовании дополнительного покровного слоя с высоким показателем преломления. Показано, что адиабатическая деформация волноводных мод позволяет повысить поглощение света в сверхпроводящей пленке до уровня $\sim 1 \mathrm{~dB} / \mu \mathrm{m}$, что дает возможность изготовить на ниобате лития детектор одиночных фотонов с квантовой эффективностью порядка $70 \%$.
\end{abstract}

Ключевые слова: датчик одиночных фотонов, оптический волновод, ниобат лития, оптическая мода, интегральная оптика, квантовая фотоника.

DOI: 10.21883/PJTF.2020.16.49853.18344

Одна из актуальных задач интегральной квантовой фотоники - создание приборной базы интегрально-оптических устройств, способных обеспечить работу квантовых оптических линий связи [1]. Ниобат лития $\left(\mathrm{LiNbO}_{3}\right)$ является одним из базовых материалов интегральной оптики [2,3]. Хорошо отработанная технология изготовления оптических волноводов, а также наличие эффективных механизмов управления оптическим излучением [2-4] делают интегрально-оптические устройства на подложках ниобата лития весьма перспективными и для квантовых информационных систем. На базе ниобата лития был продемонстрирован целый ряд квантовых интегрально-оптических устройств, таких как источники спутанных фотонов, модуляторы, когерентные преобразователи длины волны, устройства квантовой памяти [1]. Наиболее проблемным элементом квантовой фотоники для реализации на ниобате лития являются детекторы одиночных фотонов.

Сверхпроводящие детекторы одиночных фотонов уже реализованы на нескольких видах полупроводниковых подложек [5], однако попытки создать интегральные детекторы на ниобате лития [6-8] не были столь успешными: изготавливаемые детекторы имели малую эффективность, на порядки меньшую, чем требуется для практических приложений.

Цель настоящей работы состоит в поиске путей повышения чувствительности интегрально-оптического сверхпроводящего детектора одиночных фотонов на основе волноводов на подложке ниобата лития и демонстрации возможности достижения величин эффективности детектирования, необходимых для работы систем квантовой фотоники.

Базовым сверхпроводящим материалом для изготовления детектора одиночных фотонов является нитрид ниобия $(\mathrm{NbN})$ [5]. Ранее было показано, что пленки $\mathrm{NbN}$ с хорошими сверхпроводящими характеристиками могут быть сформированы на подложках ниобата лития методом магнетронного напыления [9]. Помимо сверхпроводящих характеристик эффективность интегрально-оптического детектора одиночных фотонов зависит от эффективности поглощения света [5], определяемой интегралом перекрытия волноводной моды и наноразмерной волноводной структуры. Для стандартных волноводов, изготавливаемых на подложке ниобата лития методом термической диффузии титана, область взаимодействия оптического излучения, распространяющегося по волноводу, с нанометровой пленкой на его поверхности составляет ничтожные $0.05 \%$ от общей площади модового пятна диаметром $\sim 10 \mu \mathrm{m}$. Оценка оптических потерь, вызванных пленкой $\mathrm{NbN}$ толщиной $5 \mathrm{~nm}$, составляет всего лишь $\sim 1 \cdot 10^{-3} \mathrm{~dB} / \mu \mathrm{m}$.

Авторами работы предложено использовать дополнительный покровный слой с высоким показателем преломления, который формируется поверх сверхпроводящей наноструктуры $\mathrm{NbN}$. В качестве материала покровного слоя был рассмотрен нитрид кремния $\left(\mathrm{SiN}_{x}\right)$, имеющий пренебрежимо малые потери в покровном слое и варьируемый в широких пределах $\left(n_{\operatorname{SiN}_{x}} \approx 2-3\right)$ в зависимости от концентрации кремния показатель преломления пленки [10]. Предлагается использовать 

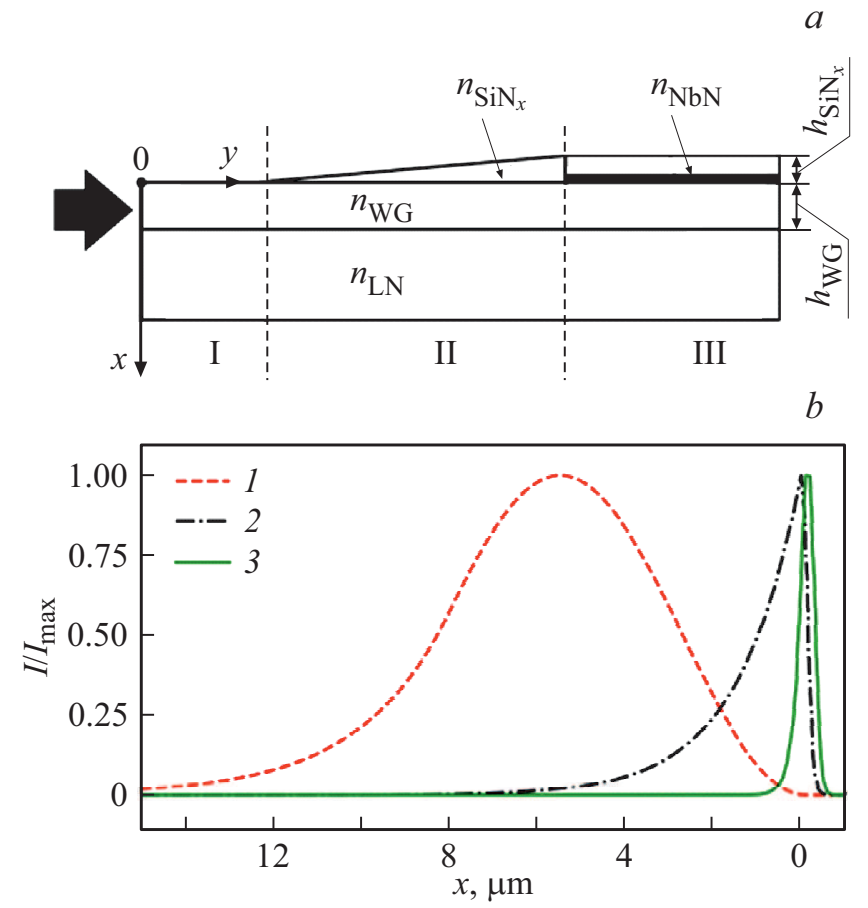

Рис. 1. $a-$ конфигурация интегрально-оптического сверхпроводящего детектора одиночных фотонов на основе титандиффузного волновода на подложке ниобата лития с покровным слоем. I - область ввода оптического излучения, II - адиабатический переход, III - область поглощения и детектирования оптического излучения. $b-$ распределение интенсивности в волноводной моде. 1 - мода волновода в ниобате лития (участок I), 2 - деформированная фундаментальная мода адиабатического перехода (участок II), 3 - мода покровного слоя (участок III).

пленки с относительно высокой концентрацией кремния и соответственно высоким показателем преломления $n_{\mathrm{SiN}}=2.5$, что обеспечит необходимый контраст с подложкой ниобата лития (обыкновенный и необыкновенный показатели преломления двулучепреломляющего кристалла $\mathrm{LiNbO}_{3}$ равны $n_{o}=2.21$ и $n_{e}=2.14$ соответственно).

Теоретический анализ повышения эффективности взаимодействия оптического излучения со сверхпроводящей пленкой проводился методом конечных элементов с использованием программного пакета COMSOL Multiphysics. Исходя из численного расчета мод волноводных структур определялись оптические потери, связанные с мнимой частью постоянной распространения. Для проведения теоретического анализа была использована упрощенная двумерная модель, в которой градиентный волновод на подложке ниобата лития $X$-среза был заменен на планарный волновод со ступенчатым профилем показателя преломления (рис. $1, h_{\mathrm{WG}}=8 \mu \mathrm{m}$, $n_{\mathrm{WG}}=n_{\mathrm{LN}}+2 \cdot 10^{-3}$ ), одномодовый в телекоммуникационном диапазоне длин волн $(1500-1600 \mathrm{~nm})$. Анализ проводился без учета анизотропии для одной поляризационной ТЕ-моды, соответствующей необыкновенной волне $\left(n_{\mathrm{LN}}=n_{e}=2.14\right)$, поскольку именно данная поляризационная мода наиболее часто используется из-за более высоких электрооптических и нелинейных оптических характеристик $[11,12]$. Ранее данная модель была использована для анализа интегрально-оптических делителей мощности на подложках ниобата лития [13,14], и, несмотря на значительные упрощения, было продемонстрировано хорошее согласие с экспериментальными данными.

Предлагаемая новая конфигурация сверхпроводящего детектора может быть разделена на три участка (рис. $1, a)$ : I - область ввода оптического излучения, II - адиабатический переход, III - область поглощения и детектирования оптического излучения.

Область ввода оптического излучения представляет собой стандартный одномодовый титан-диффузный волновод (рис. 1, $a$ ), оптимизированный для стыковки с телекоммуникационным оптическим волокном (SMF 28) (рис. 1, b, кривая 1 ).

В области поглощения и детектирования (III) на поверхности волновода сформирована нанометровая сверхпроводящая пленка $\mathrm{NbN}$ толщиной $h_{\mathrm{NbN}}=5 \mathrm{~nm}$, которая покрывается слоем нитрида кремния. Поскольку условия работы детектора единичных фотонов требуют приложения к пленке тока смещения, близкого к критическому (ширина сверхпроводящей щели мала), для анализа взаимодействия оптического излучения с пленкой можно использовать характерный для несверхпроводящего состояния комплексный показатель преломления $\mathrm{NbN}\left(n_{\mathrm{NbN}}=5.23+5.28 i\right)[15]$. В данной работе была рассмотрена сплошная пленка $\mathrm{NbN}$, в то время как в реальных детекторах одиночных фотонов используются структуры в виде меандра $[5,6]$. Характерные размеры сформированной из пленки сверхпроводящей структуры $\sim 100 \mathrm{~nm}$, что существенно меньше длины волны, поэтому наличие наноструктуры может быть учтено введением эффективного средневзвешенного показателя преломления между пленкой и покровным слоем нитрида кремния.

Толщина покровного слоя на участке III выбирается такой, чтобы в ней существовала собственная оптическая мода, поле которой за счет подбора высоты покрывающего слоя будет иметь большую площадь перекрытия с площадью сверхпроводящей структуры из нитрида ниобия и, как следствие, сильно с ней взаимодействовать. Как следует из проведенных расчетов (рис. 2, $b$ ), оптимальная толщина покровного слоя, при которой наблюдается максимальное поглощение в сверхпроводящей пленке, $h_{\mathrm{SiN}_{x}} \approx 300 \mathrm{~nm}$ соответствует условию минимального поперечного распределения интенсивности волноводной моды покровного слоя. Следует отметить, что достижимые значения оптических погонных потерь на три порядка выше, чем в детекторе без покровного слоя ( $\sim 1 \mathrm{~dB} / \mu \mathrm{m}$ против $1 \cdot 10^{-3} \mathrm{~dB} / \mu \mathrm{m}$, рис. $\left.2, b\right)$. При увеличении толщины покровного слоя эффективность взаимодействия со сверхпроводящей пленкой падает (рис. 2, $b$ ). 


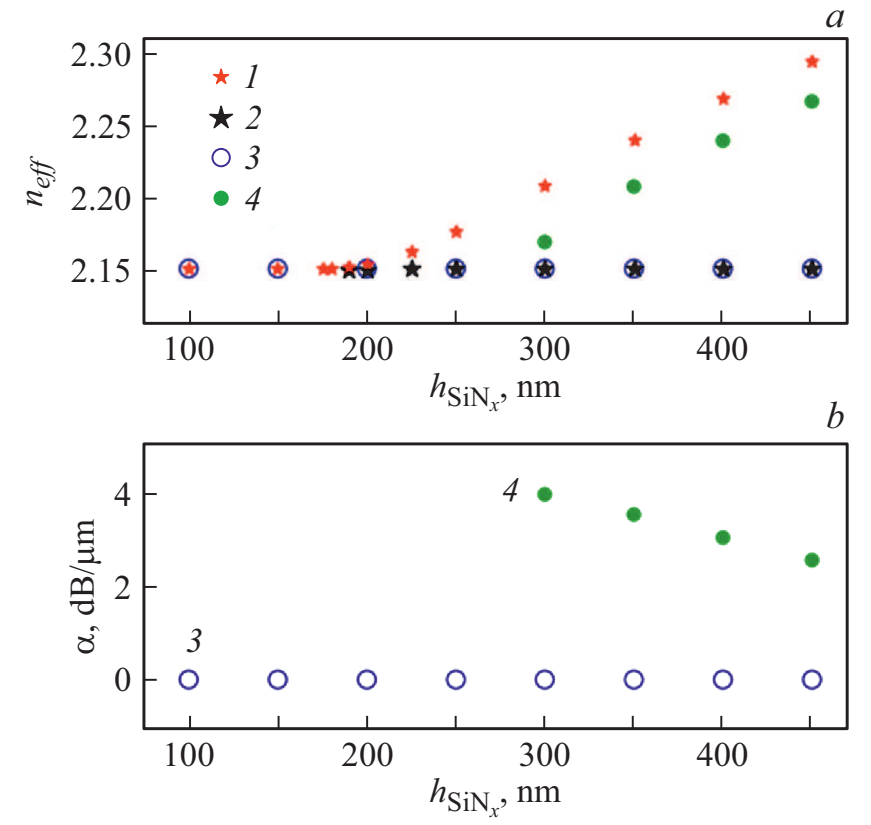

Рис. 2. Эффективный показатель преломления $(a)$ и погонные оптические потери $(b)$ волноводных мод в области поглощения и детектирования оптического излучения в зависимости от толщины покровного слоя. 1,2 - моды (фундаментальная и первая высшая соответственно) адиабатического перехода (рис. 1, $a$, участок II), 3 - мода покровного слоя в области поглощения, 4 - мода волновода ниобата лития под слоем $\mathrm{NbN}$ (рис. 1, $a$, участок III).

Сверхпроводящая пленка в области поглощения и детектирования оптического излучения (III) играет роль металлического зеркала, препятствуя проникновению оптического излучения из ниобата лития в нитрид кремния. Для возбуждения моды покровного слоя в конфигурацию детектора был введен адиабатический переход, где происходит преобразование моды титан-диффузного волновода в ниобате лития на участке I в моду покровного слоя на участке III. Он выполнен при плавном увеличении толщины покровного слоя $h_{\mathrm{SiN}_{x}}$, которое может быть реализовано, например, специальными технологиями многостадийного травления. По мере увеличения толщины покровного слоя на участке II, где отсутствует отражающая сверхпроводящая пленка, излучение все сильнее локализуется в покровном слое (рис. 2,a). Оптическая мода при увеличении толщины пленки $h_{\mathrm{SiN}_{x}}$ постепенно деформируется, ее показатель преломления возрастает (рис. 2, $a$ ), а при пороговой толщине $h_{\mathrm{SiN}_{x}} \approx 190 \mathrm{~nm}$ волноводная структура становится двухмодовой (рис. 2,a). Высшая мода в рассмотренном диапазоне $h_{\mathrm{SiN}_{x}}$ остается локализованной в ниобате лития, а фундаментальная с ростом толщины покровного слоя все сильнее концентрируется в нитриде кремния, что обеспечивает плавное перетекание мощности этой моды в собственную моду покровного слоя на участке III, где и происходит эффективное поглощение оптической мощности сверхпроводником $\mathrm{NbN}$.
Таким образом, в настоящей работе предложен метод усиления взаимодействия света в волноводе на подложке ниобата лития со сверхпроводящей наноструктурой нитрида ниобия на его поверхности, что потенциально повысит квантовую эффективность работы сверхпроводящего детектора одиночных фотонов на три порядка. При условии правильно оптимизированной топологии от таких детекторов можно ожидать эффективность на уровне $70 \%$, что соответствует требованиям современных систем квантовой фотоники [5].

\section{Финансирование работы}

Работа выполнена при финансовой поддержке Российского фонда фундаментальных исследований (проект № 18-07-01174).

\section{Конфликт интересов}

Авторы заявляют, что у них нет конфликта интересов.

\section{Список литературы}

[1] Alibart O., D'Auria V., De Micheli M., Doutre F., Kaiser F., Labonté L., Lunghi T., Picholle E., Tanzilli S. // J. Opt. 2016. V. 18. N 10. P. 104001.

[2] Bazzan M., Sada C. // Appl. Phys. Rev. 2015. V. 2. N 4. P. 040603.

[3] Wooten E.L., Kissa K.M., Yi-Yan A., Murphy E.J., Lafaw D.A., Hallemeier P.F., Maack D., Attanasio D.V., Fritz D.J., McBrien G.J., Bossi D.E. // IEEE J. Sel. Top. Quant. Electron. 2000. V. 6. N 1. P. 69-82.

[4] Alferness R. // IEEE J. Quant. Electron. 1981. V. 17. N 6. P. 946-959.

[5] Ferrari S., Schuck C., Pernice W. // Nanophotonics. 2018. V. 7. N 1. P. $1725-1758$.

[6] Agruzov P., Ionov A., Chekmazov S., Bozhko S., Ilichev I., Tronev A., Parfenov M., Shamrai A. // 2019 Conf. on Lasers and Electro-Optics Europe \& European Quantum Electronics Conf. (CLEO/Europe-EQEC 2019). IEEE, 2019. DOI: 10.1109/CLEOE-EQEC.2019.8871852

[7] Tanner M.G., San Emeterio Alvarez L., Jiang W., Warburton R.J., Barber Z.H., Hadfield R.H. // Nanotechnology. 2012. V. 23. N 50. P. 505201.

[8] Höpker J.P., Gerrits T., Lita A., Krapick S., Herrman H., Ricken R., Quiring V., Mirin R., Nam S.W., Silberhorn C., Bartley T.J. // APL Photon. 2019. V. 4. N 5. P. 056103. DOI: $10.1063 / 1.5086276$

[9] Ionov A.M., Chichkov V.I., Shamrai A.V., Ilïhev I.V., Ksenz A.S., Orlov V.I., Egorov S.V., Shvets I.V., Bozhko S.I. // Mater. Lett. 2020. V. 260. P. 126918. DOI: 10.1016/j.matlet.2019.126918

[10] Ng D.K.T., Wang Q., Wang T., Ng S.K., Toh Y.T., Lim K.P., Yang Y., Tan D.T.H. // ACS Appl. Mater. Interfaces. 2015. V. 7. N 39. P. 21884-21889. DOI: 10.1021/acsami.5b06329

[11] Parfenov M., Agruzov P., Ilichev I., Shamray A. // J. Phys.: Conf. Ser. 2016. V. 741. N 1. P. 012141.

[12] Ильичев И.В., Тогузов Н.В., Шамрай А.В. // Письма в ЖТФ. 2009. Т. 35. В. 17. С. 97-103. 
[13] Парфенов М.В., Тронев А.В., Ильичев И.В., Агрузов П.М., Шамрай А.В. // Письма в ЖТФ. 2020. Т. 46. В. 1. С. 8-11.

[14] Парфенов М.В., Тронев А.В., Ильичев И.В., Агрузов П.М., Шамрай А.В. // Письма в ЖТФ. 2019. Т. 45. В. 5. С. 3-5.

[15] Hu X., Holzwarth C.W., Masciarelli D., Dauler E.A., Berggren K.K. // IEEE Trans. Appl. Supercond. 2009. V. 19. N 3. P. $336-340$. 